\title{
Spine Surgery Database: A Turkish Registry for Spinal Disorders
}

\section{Omurga Cerrahisi Veri Tabanı: Türkçe Omurga Hastalıkları Arșivi}

\begin{abstract}
AIM: This study presents a Turkish academic database application platform which is specialized for spinal surgery clinics. The application provides a userfriendly interface and easy access to the patients' data due to a hierarchical structure. Patient diagnosis, treatment and follow-up process data are recorded regularly and systematically. Another ambitious goal is to register the treatment outcomes to also provide an environment for analyzing patients' data.

MATERIAL and METHODS: The Spine Surgery Database (SSD) application was designed as incorporating all content that can be used in the field of spine surgery expertise. The system has different tools for different purposes; main application, database creation, analysis and data merge tool. Widely accepted standards, Oswestry Disability Index, Prolo Scale, SF-36, etc., are used to assess outcome analysis.

RESULTS: Diagnosis, treatment and follow-up processes were monitored in a standard structure. Distributions of general patient profile over pathological and anatomical information are represented using the SSD analysis tool. Over 22.000 patients' medical data were successfully recorded and the patient registration problem was resolved by using software applications.

CONCLUSION: This specialized application presents a user-friendly interface which supplies all needs of spinal surgery. Questionnaires and scales which are very important for clinicians and researchers can be generated through the SSD tool.
\end{abstract}

KEYWORDS: Spine surgery, Database, Outcome analysis

\section{ÖZ}

AMAÇ: Omurga cerrahi klinikleri için özel olarak geliştirilmiş olan ilk Türkçe akademik veri tabanıdır. Uygulama, kullanıcı dostu bir arayüzle hasta verilerine hiyerarşik bir yapıda kolay ulaşım sağlamaktadır. Hasta teşhis, tedavi ve takip süreci verileri, sistematik olarak ve düzenli bir şekilde kaydedilir. Çalışmanın diğer iddialı amacı da, tedavinin sondurumlarını kaydetmek ve bunun yanında hasta verilerini analiz eden bir ortam sunmaktır.

YÖNTEM ve GEREÇ: Omurga Cerrahisi Veri tabanı (OCV) uygulaması, omurga cerrahisi uzmanlık alanında kullanılabilen bütün içeriği kapsayacak şekilde tasarlanmıştır. Sistem farklı amaçlara hizmet eden araçlardan oluşmaktadır; ana uygulama, veri tabanı oluşturma aracı, analiz ve veri birleştirme aracı. Yaygın olarak kullanılan standartlardan; Oswestry Sakatlık İndeksi (ODI), Prolo Skalası, SF-36 gibi standartlar sondurum analizi değerlendirilmesi için kullanılmıştır.

BULGULAR: Hasta verilerinin standart bir yapıda takip edildiği bir sistem tasarımlanmıştır. Patolojik ve anatomik bilgiler doğrultusunda genel hasta profil dağılımı SSD analiz bölümüyle sunulmuştur. Spinal cerrahi ile yoğun olarak ilgilenen bir akademik merkezde, 22.000 den fazla hasta verisi başarılı bir şekilde kayıtlanmış ve spinal cerrahi hastalarının kayıt sorunları yazılım uygulamaları ile çözülmüş̧ür.

SONUÇ: Bu özelleştirilmiş uygulama omurga cerrahisi hastalarının tüm ihtiyaçını karşılayacak kullanışlı bir arabirim sunmaktadır. Klinisyenler ve araştırmacılar için önem teşkil eden tüm anket ve skalalar OCV ile elde edilebilmektedir.

ANAHTAR SÖZCÜKLER: Omurga cerrahisi, Veri tabanı, Sondurum analizi

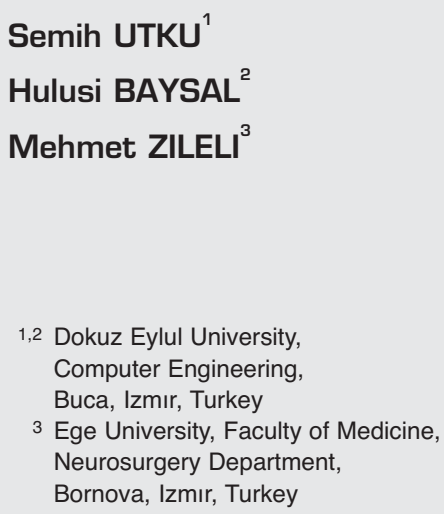

Received : 25.08.2009

Accepted : 06.11.2009

Correspondence address: Semih UTKU

Phone : +90 2324127428

Fax : +90 2324127402

E-mail : semih@cs.deu.edu.tr 


\section{INTRODUCTION}

It is clear that patients should be recorded and registered in a basic and standard ways in technology-driven surgical disciplines. Computerbased medical records totally have now taken the place of paper-based medical records in order to provide specialists a faster and more systematic way to keep and gather medical data $(18,21,23,27,29,32)$. Using computer-assisted patient recording systems brings several advantages including increased efficiency of administration, reduction of data entry errors, improved ability to solicit sensitive or confidential information, elimination of paper storage, and the potential for automatic scoring and report generation $(5,17,25)$. In health care systems, large amounts of biological, clinical and administrative data are stored in clinical repositories to identify and integrate patient information for research and utilization objectives $(2,22)$.

It is crucial to keep patients' data regularly and systematically and to have easy access to these data during diagnosis, treatment and follow-up phases in spine surgery clinics (15). Clinical information, symptoms, radiological examination, results of other reviews and patients' scores before and after surgery must also be followed-up. When there is a huge increase in the number of patients, it becomes more difficult to follow-up patients due to rise in data. A potentially large amount of data and lack of multilanguage support creates a necessity in this area.

Various applications and methods are used to record patient data by specialists. Existing applications in the field of spine surgery do not provide sufficient detail and ease of data entry to the specialist. These applications organize the patients' clinical data, but they have some disadvantages, such as difficulties in managing the patient followup process and lack of multi-language support. Choosing a software application involves balancing several competing factors. These include cost, ease of use, the availability of technical support and maintenance, recognition of the inherent limitations imposed by the software, consideration of existing database platforms, and compatibility with other applications (9). SSD (Spine Surgery Database) was developed to fill these gaps in spine surgery clinics.

Clinical data analysis used to improve healthcare system and to establish quality benchmarks have a potential impact demonstrated by recent reports of the Medicine Institute (8). Indeed, databases are important and widely used tools in science including modern medical practice and clinical research (2). A database has been defined as a structured repository of data that allows for ongoing data collection, modification, and retrieval $(6,7)$. Data which will be used in the health care systems should be carefully defined when designing medical databases. In general, it is preferable to be as precise as is meaningful and to record quantitative rather than qualitative measures. Storage of patient data in spinal surgery clinics more regularly and with all the detail and managing the follow-up process in detail, and more importantly to access all data at any time and swiftly are important steps. First of all, this study was intended as a Turkish academic database program to reach these goals. In this program, patient data are kept systematically and implemented for easy access. We also wanted to develop a comprehensive database structure that contained all data in spinal surgery clinics and to submit an interface to access the outcome analysis results by using these data.

\section{MATERIALS and METHODS}

The Spine Surgery Database application was designed as incorporating all contents that can be used in the field of spine surgery expertise. This application presents a simple usage together with its most complicated data entry due to its hierarchical structure. In this context, preparation of required content that matters for this study and substructure analysis for software were started in 2006. After the arrangements and error controls, the study was concluded in 3 years.

Spine Surgery Database software was designed according to run with Windows operating system. Software was developed by VB. NET programming language by using. NET Framework substructure. The Microsoft. NET Framework is a software framework that can be installed on computers running Microsoft Windows operating systems. It includes a large library of coded solutions to common programming problems and a virtual machine that manages the execution of programs written specifically for the framework. The. NET Framework is a key Microsoft offering and is intended to be used by most new applications created for the Windows platform. Microsoft SQL Server 2005 was preferred as database working in harmony with NET platform. 
Stored procedures are entirely used to query all required data in application. While stored procedures are handled at the server side, they are more effective and safe method to perform queries (20). Application has various data types like tables as seen in Figure 5. These kinds of data are stored using XML (Extensible Markup Language) technology in databases. XML is designed as a markup language to standardize data. Complex data of the application are stored in database as XML $(4,28)$.

System is composed of software fragments which handles different functions:

Main Application: The interface which users search, input and list user data. The most commonly used part of the system by the specialists. Because of this, the interface contains visual elements such as image buttons and keyboard shortcuts.

Database Creation Tool: The application which prepares database for first-use. System uses SQL Server as database. Database should be prepared before using system. This tool creates all tables which are used application and makes system ready for first use.

Data Merge Tool: The application which compares and merges data on different systems to make them up-to-date. Data merging is a big problem in systems which allows multiple data entries. This tool helps specialists when choosing the different data entered for the same patient by listing conflicted items.

a) Work-flow: The system has 7 different modules to provide a fast and effective way to input and analyze patient data.

Patient Search/List Module

Patient General Info Module

Medical History / General Information Module

Diagnosis Module

Treatment Module

Follow-up Module

Multimedia Module

General work-flow of the system is depicted in Figure 1.

System has two different work principles for new and existing patients. If patients' record does not exist in system, patients are recorded with brief information. If the patient had been recorded before, a more detailed "Patient Search/Listing Page"

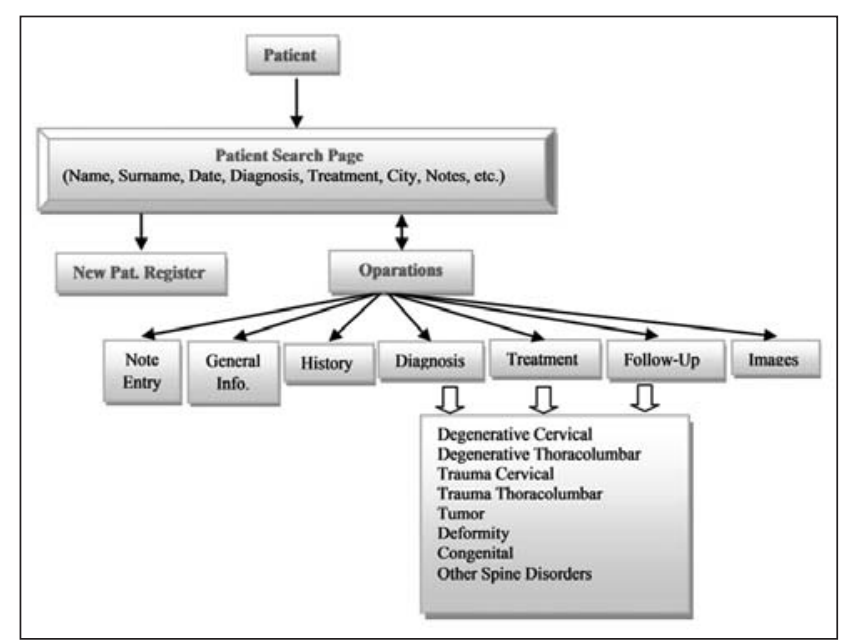

Figure 1: System Overview.

becomes accessible. These search pages direct to "Patient Operation Page" (Patient General Information Form) which is filled for the patient. The patient search process can be done according to one parameter or more parameters. This process provides quick access to the patient data. Existing patients can be searched by name, surname, and arrival date. At the same time, the search process can be run by using diagnosis, notes related with treatment of patient. The results of each search list can be recorded in Excel format on the disk, so that patient data can be examined and analyzed later.

The "Patient General Information Form" is a module which is used for quick information entry at basic level and access to the other details. The module is designed to allow users an effective and quick usage of the system. There is a detailed notetaking editor which contains patient information, general illness data, accessing the other modules and notes related with the patient. The most important part of patient general information module is diagnosis selection. "Anatomical Diagnosis" and "Pathological Diagnosis" can be appointed from sub windows of each diagnosis type. Each selected field under "Pathological Diagnosis" allows determining Diagnosis - Treatment - Follow up fields. Under Diagnosis-Treatment-Follow up sub-forms are activated in accordance with values.

Most of the fields in whole system are determined from selective areas. When the user chooses the data entry field, selected area activates and intended information can be signed and added. By this means, user can enter data quickly and consistently. 
b) Diagnosis Modules: 2 types of diagnosis can be chosen for all patients.

1- Anatomical Diagnosis: Steps of this diagnosis are Cervical, Cervicothoracic, Thoracic, Thoracolumbar, Lumbar, Sacral, All Spine, Craniocerebral, Peripheral Nerve. More than one localization can be chosen.

2- Pathological Diagnosis: Steps of this diagnosis are Degenerative Cervical, Degenerative Thoracolumbar, Trauma Cervical, Trauma Thoracolumbar, Tumor, Deformity, Congenital, Other Spine Disorders. More than one localization can be chosen.

There are a lot of sub-steps for pathological diagnosis. All clinical and radiological information, patient scores with surgical and medical treatment can be processed using these sub-steps. First of all, one of the types of "Pathological Diagnosis" must be signed to reach these sub-steps. Later, related information can be marked by selecting relevant points in the "Diagnosis" and "Treatment" boxes.

c) Treatment Module: There are many pages about detailed scales, measurement and operation techniques in 6 types of treatment modules. (1) Degenerative Cervical, (2) Degenerative Thoracolumbar, (3) Trauma Cervical, (4) Trauma Thoracolumbar, (5) Tumor, (6) Deformity

d) Follow-up Module: The patient follow-up process is also important for the clinicians. All patients should be followed up in order to assess the risks and benefits of a certain therapy. In many cases of spinal surgery, this can only be done after a minimum of 3-6 months followed by the surgery. Monitoring treatment process periodically is essential for achievement of treatment. For this reason, this study aims that follow-up process forms accordance with patient pathologic diagnosis. The important point of this module is that diagnosis periods are made individually and considering of patient visit time if the patients have had one more pathologic diagnosis. This study contains essential arrangements for the diagnosis periods.

e) Recording Figures and Videos: Patients' digital data - patients' direct radiograms, CT and MR images, other patient figures and videos- are usually not accesses on time and they exist in different places. Thus, there are problems about patient diagnosis, treatment and follow-up process. Speialists can access these data from one location and on time with this system, so this operation provides efficiency to the expert. In this study, a multimedia module was designed to ensure these needs. Patients' digital data can be loaded into the system and displayed by date.

User Tools: During the study, presentation of many obtained data and fast and efficient usage by the user of these data were examined; different solution was presented with friendly user interfaces. Figure 2 shows "Patient Main Form". A few examples about interfaces are on Figure 3, 4 and 5. Specialists can take notes about patient, decide

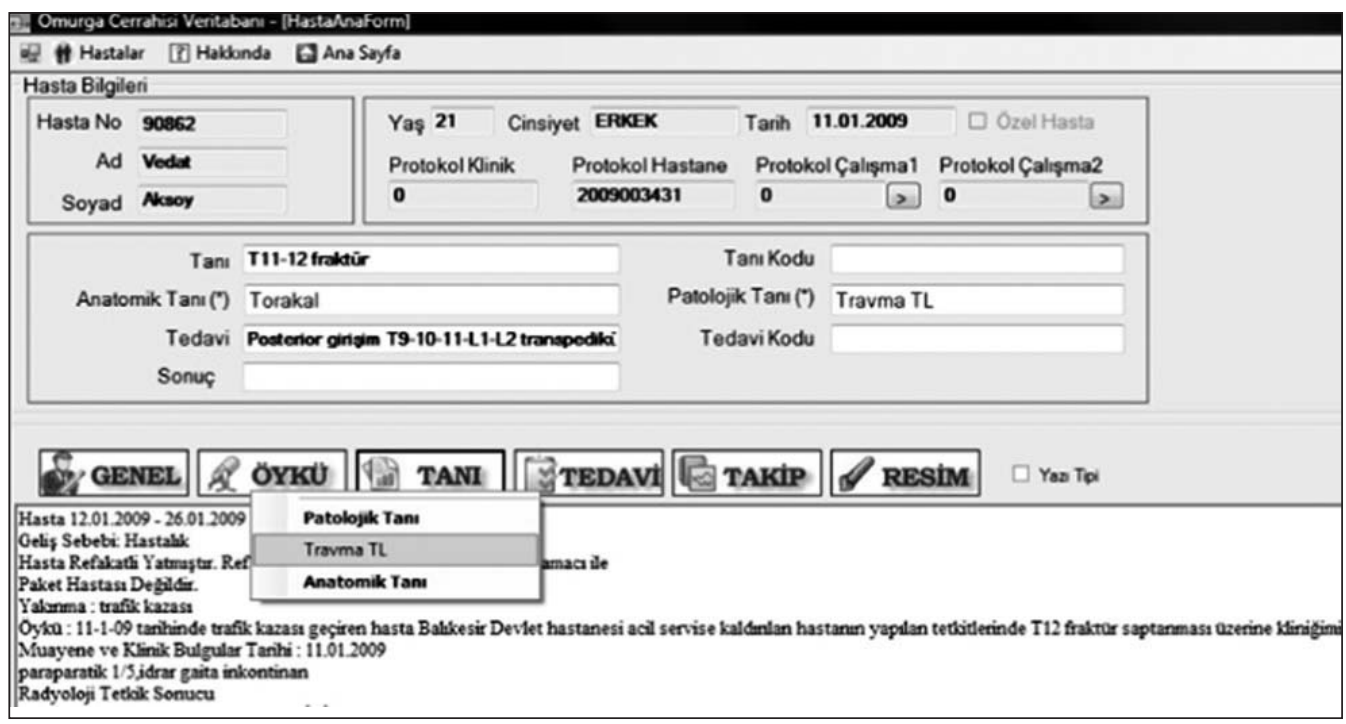

Figure 2: Patient Main Form. 


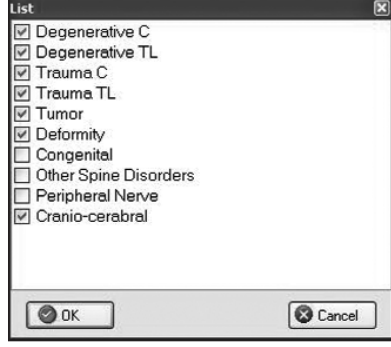

Figure 3: Pathologic

Diagnosis Choices.

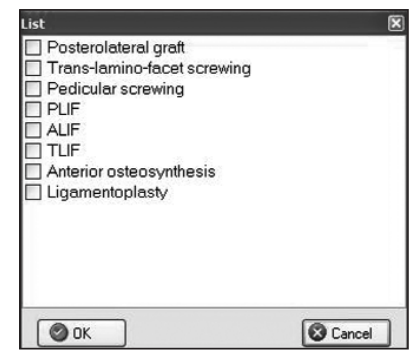

Figure 4: Pop-up Windows in Sub-forms.

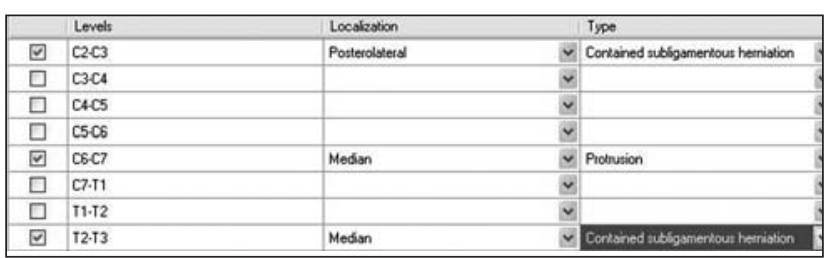

Figure 5: Complex data structures are displayed using compound form elements. anatomic and pathologic diagnosis and connect the other module with this form.

In an academic department busy with spine surgery patients, data entry of over 22.000 patients was successfully entered and problems of spine surgery data registry were solved with soft ware applications. Table I shows a simple analysis of pathological diagnosis created by excel program in 2246 patients with age distribution. Table II shows analysis of anatomical diagnosis created by the Excel program in 2355 patients with age distribution. Figure 6 depicts histogram of the Table I and Figure 7 depicts histogram of Table II. There are also tools to search patients with simple key words from diagnosis, treatment or notes entries.

\section{DISCUSSION}

There is now growing awareness among spine surgeons of the advantages in using registers to

Table I: Profile of Pathological Diagnosis and Ages of a Subset of Patients in SSD

\begin{tabular}{|l|c|c|c|c|c|c|c|c|}
\hline Age & $\begin{array}{c}\text { Degenerative } \\
\text { Cervical }\end{array}$ & $\begin{array}{c}\text { Degenerative } \\
\text { Thoracolumbar }\end{array}$ & $\begin{array}{c}\text { Trauma } \\
\text { Cervical }\end{array}$ & $\begin{array}{c}\text { Trauma } \\
\text { Thoracolumbar }\end{array}$ & Tumor & Deformity & $\begin{array}{c}\text { Congenital } \\
\text { Other Spine } \\
\text { Disease }\end{array}$ \\
\hline $10-20$ & 4 & 16 & 10 & 6 & 27 & 12 & 11 & 0 \\
\hline $20-30$ & 18 & 97 & 14 & 20 & 21 & 4 & 6 & 0 \\
\hline $30-40$ & 72 & 215 & 13 & 15 & 34 & 6 & 6 \\
\hline $40-50$ & 110 & 313 & 10 & 13 & 43 & 2 & 13 & 2 \\
\hline $50-60$ & 99 & 300 & 13 & 16 & 62 & 1 & 0 \\
\hline $60-70$ & 70 & 247 & 8 & 15 & 48 & 1 & 2 \\
\hline$>70$ & 34 & 147 & 5 & 16 & 20 & 3 & 0 & 3 \\
\hline Total & 407 & $\mathbf{1 3 3 5}$ & $\mathbf{7 3}$ & $\mathbf{1 0 1}$ & $\mathbf{2 5 5}$ & $\mathbf{2 9}$ & $\mathbf{3 8}$ & $\mathbf{8}$ \\
\hline
\end{tabular}

Table II: Profile of Anatomical Diagnosis and Ages of a Subset of Patients in SSD

\begin{tabular}{|c|c|c|c|c|c|c|c|}
\hline Age & Cervical & Cervico-thoracic & Thoracic & Thoracolumbar & Lumbar & Sacral & All Spine \\
\hline $10-20$ & 22 & 2 & 11 & 9 & 29 & 10 & 4 \\
\hline $20-30$ & 44 & 0 & 18 & 9 & 110 & 7 & 2 \\
\hline $30-40$ & 107 & 3 & 16 & 12 & 228 & 5 & 4 \\
\hline $40-50$ & 152 & 0 & 20 & 8 & 345 & 7 & 0 \\
\hline $50-60$ & 136 & 0 & 40 & 17 & 322 & 10 & 2 \\
\hline $60-70$ & 90 & 0 & 24 & 8 & 286 & 5 & 0 \\
\hline$>70$ & 39 & 0 & 18 & 9 & 164 & 1 & 0 \\
\hline Total & 590 & 5 & 147 & 72 & 1484 & 45 & 12 \\
\hline
\end{tabular}




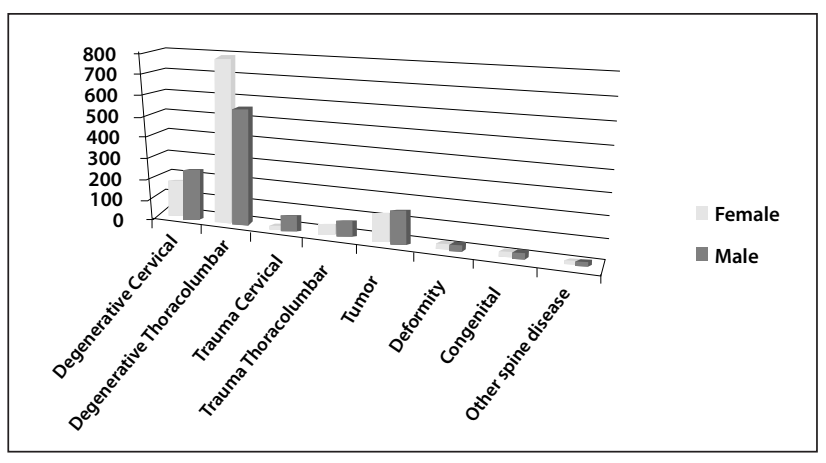

Figure 6: Histogram - Profile of pathological diagnosis and ages of a subset of patients in SSD.

facilitate the analyses and reporting of treatment outcome (13). Registers have the potential to provide information about the number and type of surgical interventions, adverse events and outcomes such as patient satisfaction, quality of life and costeffectiveness $(12,19)$. In the narrowest sense, "outcomes" refers to what patients experience as a result of a disease and its treatment (14).

If the working conditions and requirements of the user are considered, reliable and quick access to patient data is critical. All these assessments were therefore made during the study. A system was designed where patients' data was entered regularly, and the diagnosis, treatment and follow-up processes were monitored in a standard structure. The designed system was prepared in a format where different user groups could be defined in and privatized with restrictions for the groups. A userfriendly interface was created. The patients can be searched fast and with different combinations. A database was designed to record the detailed patient data by considering all clinical applications. The form components have the capability to save Multimedia data. On the other hand, system data safety was secured by use of data backup to prevent failure of recorded data. If the following characteristics of "Spine Surgery Database" are considered, the SSD has some advantages;

- Diagnosis \& follow up data are recorded regularly

- Complications are recorded methodically

- Multimedia data like film, figure and video are easily associated with patients

- Protocols are easily adapted into the system

- Patients are searched in a hierarchic structure easily

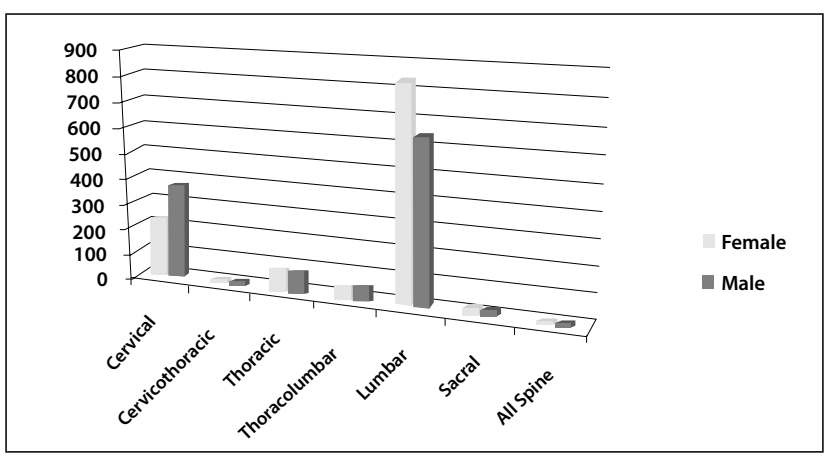

Figure 7: Histogram - Profile of anatomical diagnosis and ages of a subset of patients in SSD

- Self-Report Questionnaires and scales modules for Outcome Analyses

Data collection is dedicated to measurement of clinical outcomes (31). A registry is defined as a database of identifiable persons containing a clearly defined set of health and demographic data collected for a specific public health purpose. Eight requirements are identified as crucial for the successful development of a new registry. They include an implementation plan, adequate documentation, quality control procedures, case definition and case finding (ascertainment) procedures, determination of data elements, data collection and processing procedures, data access policy, and a framework for dissemination of registry data and findings (26).

A HIS (Hospital Information System) is designed to manage the administrative, financial and clinical aspects of a hospital. A perfect database system seems to be associated with HIS systems. However, the Spine Surgery Database (SSD) system does not intend to be a part of whole hospital systems. This is an academic database system focused on spinal disorders. The SSD is designed to register patient data with necessary protocol numbers used in HIS. Also, the SSD has a flexible database structure. Therefore, several coding mechanisms (e.g. the Social Security Institution in Turkey) can be added to the system. In this study, patient data was divided into sub-categories as general information, history, diagnosis, treatment and follow-up. The general information category consisted of a field which keeps common data such as individual information, address, telephone number, and reference center for each patient. General information data are also used for detailed search processes of the patients. 
History category is comprised of patients' information which has the content of anamnesis data, pathological data, and previously applied medical and surgical treatments. Diagnostic classifications and diagnostic data of patients are entered into the detailed sub-forms prepared separately for each diagnosis. Two types of diagnosis can be entered into the system as "anatomical" and "pathological" for each patient. Different pathological diagnosis sub-forms can be accessed by using pathological diagnosis sub-steps defined for patient. Patient treatments and followup process at different times can therefore be recorded regularly and properly.

There are a lot of applications in the market for patient data record and follow-up. This study differs from other applications with its specialized structure for the neurosurgery specialty. The study is unique in its application field as it supports the Turkish language.

Clinical success in the treatment of spinal disorders has traditionally been measured in terms of mortality, physiological changes (e.g., nerve conduction), or improvement in physical findings (e.g., weakness). More recently, outcome measures have been introduced that take into account the patients self-report of their physical function and health. Commonly used measures such as the ODI, Prolo Scale, VAS, JOA Scale, Beaujon-Lassale and SF36 (3). The Oswestry Disability Index (ODI) has become one of the principal condition-specific outcome measures used in the management of spinal disorders $(10,11)$. The SF-36 consists of 36 questions on the general health status of patients, and provides 8 specific categories of physical and emotional scores: physical functioning, rolephysical, bodily pain, general health, vitality, social functioning, role emotional and mental health (30). The Japanese Orthopaedic Association (JOA) has developed clinical symptom scores for patients with cervical spondylotic myelopathy and herniated lumbar disc separately.

Assessment of functional status by self-report questionnaires and scales has become an important task for back pain clinicians and researchers (16). All questionnaires and scales which are very important for clinicians and researchers can be generated through the SSD tool. As a result, it presents a highly effective method for outcome analysis
When the global solutions are reviewed and compared with this study, they do not have essential characteristics such as easy data entry and data synchronization on different offline computers. Spine Tango has been recommended as a comparable solution in this area (24). The general workflow of Spine Tango is based on optical forms and software which transforms paper-based media to the digital format. At first glance, using paper seems to be efficient for patient diagnosis and follow-up. In the golden age of mobile devices optical forms are no more popular due to high costs.

Spine Tango requires users to have an advanced knowledge of web applications and many of our colleagues failed with it because of the complexity and time constraints (1). Besides the problems with content and technology, an additional issue arose, which was taken very seriously by the committee: though mandatory demographic data for the creation of an online patient chart was minimal, electronical transfer of this data across regional or national borders conflicted with regulations about patient privacy in some countries if written informed consent was not given by patients or their families. SSD can be used even on lightweight devices such as netbooks which are commonly preferred. Also experts may review patients' previous data while entering new information.

\section{RESULT}

This is the first Turkish academic spine database program to be used in clinics in which spine surgery has been implemented. Using this database program, it is possible to monitor the patient data in details, to record and analyze the clinical information, results of radiological examination, other minor examinations, patient scores and operation data of common spinal diseases and surgeries. In the future, it is planned to develop a patient monitoring and follow-up web application for the Turkish spine surgeons to unite experts in one place.

\section{REFERENCES}

1. Aebi M, Grob D: SSE Spine Tango: A European Spine Registry promoted by the Spine Society of Europe (SSE). Eur Spine J 13(8):661-662, 2004

2. Arts DG, De Keizer NF, Scheffer GJ: Defining and improving data quality in medical registries: a literature review, case study, and generic framework. J Am Med Inform Assoc 9(6):600-611, 2002 
3. Bombardier C: Outcome assessments in the evaluation of treatment of spinal disorders. Introduction. Spine 25(24):30973099, 2000

4. Bray T,Paoli J,Sperberg-McQueen C.M: Extensible markup language. World Wide Web J. 4(2):29-66, 1997

5. Buffone GJ, Moreau D: A conceptual framework for managing clinical processes. Comput Nurs 15(2):53-60, 1997

6. Chamberlin D.D, Astrahan M.M, Blasgen M.W, Gray J.N, King W.F, Lindsay B.G, et al: A history and evaluation of System R. ACM 24(10):632-646, 1981

7. Codd E.F: Relational database: A practical foundation for productivity. Commun ACM 25(2):109-117, 1982

8. Drolet $\mathrm{BC}$, Johnson $\mathrm{KB}$ : Categorizing the world of registries. J Biomed Inform 41(6):1009-1020, 2008

9. Engh CA, Engh CA Jr, Nagowski JP, Hopper RH Jr. Database production and maintenance. Clin Orthop Relat Res 421:3542, 2004

10. Fairbank JC, Couper J, Davies JB, O'Brien JP: The Oswestry low back pain disability questionnaire. Physiotherapy 66 (8):271-273, 1980

11. Fairbank JC, Pynsent PB: The Oswestry Disability Index. Spine (Phila Pa 1976) 25 (22):2940-2952, 2000

12. Fritzell P, Hagg O, Wessberg P, Nordwall A: Swedish Lumbar Spine Study Group. 2001 Volvo Award Winner in Clinical Studies: Lumbar fusion versus nonsurgical treatment for chronic low back pain: a multicenter randomized controlled trial from the Swedish Lumbar Spine Study Group. Spine (Phila Pa 1976) 26(23):2521-2532, 2001

13. Fritzell $\mathrm{P}$, Stromqvist B, Hagg O: A practical approach to spine registers in Europe: The Swedish experience. Eur Spine J 15:57-63, 2006

14. Gerszten PC: Outcomes research: a review. Neurosurgery 43(5):1146 -1156, 1998

15. Gladman DD, Menter A: Introduction/overview on clinical registries. Ann Rheum Dis. 64(2):101-102, 2005

16. Grotle M, Brox JI, Vollestad NK: Cross-cultural adaptation of the Norwegian versions of the Roland-Morris Disability Questionnaire and the Oswestry Disability Index. J Rehabil Med 35(5):241-247, 2003

17. Hanscom B, Lurie JD, Homa K, Weinstein JN: Computerized questionnaires and the quality of survey data. Spine 27(16):1797-801, 2002

18. Levy B: Evolving to clinical terminology. J Healthc Inf Manag 18(3):37-43, 2004
19. Lundstrom M, Stenevi U, Thorburn W: The Swedish National Cataract Register: A 9-year review. Acta Ophthalmol Scand 80(3):248-257, 2002

20. Malvestuto F.M, Moscarini M: Query Evaluability in Statistical Databases. IEEE Trans. on Knowl and Data Eng 2(4):425-430, 1990

21. McDonald CJ: The barriers to electronic medical record systems and how to overcome them. J Am Med Inform Assoc 4(3):213-221, 1997

22. Mullins IM, Siadaty MS, Lyman J, Scully K, Garrett CT, Miller WG, et al: Data mining and clinical data repositories: Insights from a 667,000 patient data set. Comput Biol Med 36(12):13511377, 2006

23. Poissant L, Pereira J, Tamblyn R, Kawasumi Y: The impact of electronic health records on time efficiency of physicians and nurses: a systematic review. J Am Med Inform Assoc 12(5):505516, 2005

24. Röder C, El-Kerdi A, Grob D, Aebi M: A European spine registry. Eur Spine J 11(4):303-307, 2002

25. Sicotte C, Denis JL, Lehoux P: The computer based patient record: A strategic issue in process innovation. J Med Syst 22(6):431-43, 1998

26. Solomon DJ, Henry RC, Hogan JG, Van Amburg GH, Taylor J: Evaluation and implementation of public health registries. Public Health Rep 106(2):142-150, 1991

27. Sujansky WV: The benefits and challenges of an electronic medical record: much more than a "word-processed" patient chart. West J Med 169(3):176-783, 1998

28. Tian F, DeWitt D.J, Chen J, Zhang C: The design and performance evaluation of alternative XML storage strategies. SIGMOD Rec 31(1):5-10, 2002

29. Walker J, Pan E, Johnston D, Adler-Milstein J, Bates DW, Middleton B: The value of health care information exchange and interoperability. Health Aff (Millwood) Suppl Web Exclusives:W5-10-W5-18, 2005

30. Ware JE Jr, Sherbourne CD: The MOS 36-item short-form health survey (SF-36). Med Care 30(6):473-483, 1992

31. Weinstein JN, Deyo RA: Clinical research: Issues in data collection. Spine (Phila Pa 1976) 25(24):3104-3109, 2000

32. Zubcevic S, Dozic M, Catibusic F, Suljevic-Dropic V: The value of hospital data bases in the quality of patient care. Med Arh 58(1 Suppl 2):131-133, 2004 